\title{
Construction and Performance Characterization of Ion Selective Electrodes for Potentiometric Determination of Citapolarm Hydrobromide in Biological Fluids
}

\author{
AMANI S . ALTURIQI',2 , SAMAR O. ALJAZZAR ${ }^{1,2}$, \\ REDA A. AMMAR ${ }^{1,2}$ and NUWAIR KHALAF ${ }^{3}$ \\ ${ }^{1}$ Department of Chemistry, College of Science, \\ Princess Nourah Bint Abdul Rahman University, Riyadh, Saudi Arabia. \\ ${ }^{2}$ Deanship of Scientific Research, Princess Nourah Bint Abdul Rahman University, \\ Riyadh, Saudi Arabia. \\ ${ }^{3}$ Chemistry Department, College of Science, King Saud University, Riyadh, Saudi Arabia. \\ ${ }^{*}$ Corresponding author E-mail: raammar@pnu.edu.sa \\ http://dx.doi.org/10.13005/ojc/330138 \\ (Received: December 30, 2016; Accepted: February 14, 2017)

\begin{abstract}
A coated-wire ion selective electrode based on ion-pair complex of citapolarm hydrobromide (CT) with sodium tetraphenyl borate as electroactive material in the presence of dioctylphthalate (DOP) as the plasticizing solvent mediator was prepared. The electrode displays Nernstian response of $56.83 \mathrm{mV} /$ decade over the concentration range of $1.0 \times 10^{-6}$ to $1.0 \times 10^{-2} \mathrm{~mol} / \mathrm{L}$ at $25^{\circ} \mathrm{C}$. The influence of membrane composition, $\mathrm{pH}$ of the test solution and foreign ions on the electrode were investigated. The electrode was successfully applied to determination of the drug in pure form, urine and plasma by standard addition potentiometry.
\end{abstract}

Keywords: Citapolarm hydrobromide (CT), lon selective electrodes, potentiometry.

\section{INTRODUCTION}

Citalopram hydrochloride(CT) (Fig. 1), (1RS)-1-[3-(Dimethylamino)propyl]-1(4-fluorophenyl)-1,3-dihydroisobenzofuran-5carbonitrile hydrobromide, is an antide pressant drug of the selective serotonin reuptake inhibitor (SSRI). The therapeutic mechanism of action of SSRIs involves the potentiation of serotonin [5-hydroxytryptamine $(5-\mathrm{HT})]$ by the inhibition of its neuronal uptake. Serotonin is a neurotransmitter with neurons located in the raphe nuclei. Serotonergic neurons are known to play a part in sleepwakefulness cycles, thermoregulation, mood, emotional and food behaviours. A meta-analysis, including studies with fluoxetine, paroxetine, sertraline, escitalopram, and citalopram versus placebo, showed SSRIs to be effective in reducing symptoms of premenstrual syndrome, whether taken continuously or just in the luteal phase ${ }^{1}$. Citalopram 
has produced a modest reduction in alcoholic drink intake and increase in drink-free days in studies of alcoholics, possibly by decreasing desire or reducing the reward ${ }^{2}$. Citalopram has been found to reduce the symptoms of diabetic neuropathy ${ }^{3}$. Several methods have been reported for the determination of CT including spectrophotometry ${ }^{4-8}$, capillary electrophoresis ${ }^{9-11}$ gas chromatography ${ }^{12}$, thin layer chromatography ${ }^{13}$ and high performance liquid chromatography ${ }^{14,15}$. The present work describes preparation, characterization and application of coated wire electrode for continuous determination of CT in pure form and in biological fluids.

\section{EXPERIMENTAL}

\section{Reagents and materials}

Citapolarm hydrobromide (CT) was provided by Sigma-Aldrich. Sodium tetraphenyl borate (NaTPB) $\left(\mathrm{C}_{6} \mathrm{H}_{5}\right)_{4} \mathrm{BNa}$, dioctylphthalate (DOP) $\mathrm{C}_{24} \mathrm{H}_{38} \mathrm{O}_{4}$ were obtained from Sigma-Aldrich. Poly(vinyl chloride) (PVC) of high molecular mass and tetrahydrofuran (THF) were obtained from Fluka. Stock solution of CT $\left(1.0 \times 10^{-2} \mathrm{~mol} / \mathrm{L}\right)$ was prepared by dissolving the accurately weighed amount into a $100-\mathrm{mL}$ volumetric flask, which was dissolved in sufficient amount of phosphate buffer $\mathrm{pH}$ (5.3), and then the volume was brought up to the mark with the same solvent. Working solutions of the drug $\left(1.0 \times 10^{-7}\right.$ to $\left.1 \times 10^{-2} \mathrm{~mol} / \mathrm{L}\right)$ ) were freshly prepared by serial dilutions from the CT stock solution using phosphate buffer ( $\mathrm{pH}$ 5.3) as a solvent.

\section{Instrumentation}

All potentiometric measurements were carried out with an Orion (Cambridge, MA, USA) Model $701 \mathrm{~A}$ digital $\mathrm{pH} / \mathrm{mV}$-meter. Ag/AgCl electrode was used as an external reference electrode.

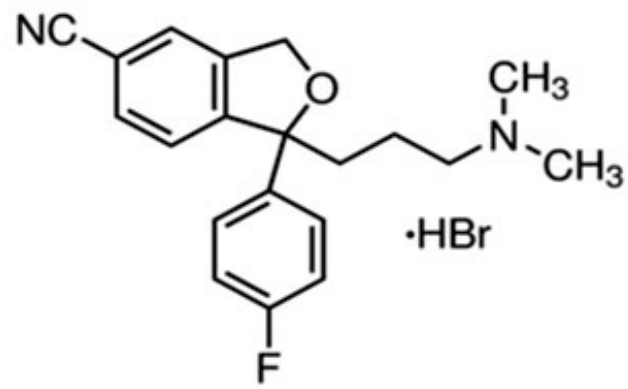

Fig. 1: Chemical structure of citapolarm hydrobromide
The electrochemical system for the membrane electrode is represented as follows: Copper/membrane/test solution// $\mathrm{KCl}$ salt bridge/ $\mathrm{Ag} / \mathrm{AgCl}$.

\section{Preparation of ion-pair compound}

The ion-pair was prepared by mixing 50 $\mathrm{ml}$ aliquots of $1.0 \times 10^{-2} \mathrm{~mol} / \mathrm{L}$ CT drug and sodium tetraphenyl borate. The resulting precipitate was filtered through G4 sintered glass crucible and washed thoroughly with deionized water, then dried at room temperature for $24 \mathrm{~h}$. The ion-pair should be stored in a desiccator. The chemical composition of the ion-pair as identified by elemental analysis was found to be 1:1 (CT-TPB).

\section{Electrode fabrication}

The membranes of optimum composition were prepared by dissolving the different amounts of ion-pair, PVC and DOP in $5 \mathrm{ml}$ THF. The solution was mixed well into a $5 \mathrm{~cm}$ diameter glass Petri dish, covered with a filter paper and left to stand overnight to allow solvent evaporation at room temperature. Copper-wire, about $1 \mathrm{~cm}$ long and $1 \mathrm{~mm}$ in diameter with a spherical head, sealed into the end of a glass tube and soldered onto a shielded cable, was dipped into the membrane solution three times, and the solvent was evaporated each time at room temperature. A membrane was formed on the copper surface; it was allowed to set for $2 \mathrm{~h}$. The electrode was then rinsed with water and finally conditioned by soaking in in $10^{-3} \mathrm{~mol} / \mathrm{L} \mathrm{CT}$ for $12 \mathrm{~h}$ before use.

\section{Construction of the calibration graphs}

The electrode was calibrated by separately transferring $50 \mathrm{~mL}$ aliquots of solutions $\left(\left(1 \times 10^{-7}\right.\right.$ to $\left.1 \times 10^{-2} \mathrm{~mol} / \mathrm{L}\right)$ of CT into a series of $100 \mathrm{~mL}$ beakers. The Prepared electrode in conjunction with the reference electrode was immersed in the above test solutions and allowed to equilibrate while stirring. The potential was recorded after stabilizing to $\pm 1 \mathrm{mV}$. The electrode was washed with phosphate buffer, $\mathrm{pH} 5.3$ between measurements. The electrode potentials, $E_{\text {elec }}$, were calculated from the e.m.f. values and plotted versus negative logarithmic concentration of $\mathrm{CT}$, Slopes of the resulting calibration curves were calculated.

\section{Electrode selectivity}

The selectivity coefficient values for the 
proposed electrode were determined by the separate solution method ${ }^{17}$, in which the following equation was applied:

$$
\log \mathrm{K}_{\mathrm{CT}, \mathrm{B}^{z^{+}}}^{\text {pot. }}=\left(\mathrm{E}_{2}-\mathrm{E}_{1}\right) / \mathrm{S}+\log [\mathrm{CT}]-\log \left[\mathrm{B}^{\mathrm{z}^{+}}\right]^{1 / \mathrm{z}^{+}}
$$

where $\mathrm{E}_{1}$ and $\mathrm{E}_{2}$ are the electrode potentials of solutions of the CT drug and interfering cation, $\mathrm{B}^{\mathrm{z}+}$ respectively $\left(1 \times 10^{-3} \mathrm{~mol} / \mathrm{L}\right.$ of both atomoxetine and the interferent) and $S$ is the slope of the calibration graph.

\section{Potentiometric determination of citapolarmý hydrobromide}

CT was determined potentiometrically using the investigated electrode by the standard addition method ${ }^{16}$. In the standard addition method, Small increments of a standard CT solution $1.0 \times 10^{-2}$ $\mathrm{mol} / \mathrm{L}$ were added to $50 \mathrm{~mL}$ aliquot samples of various drug concentrations. The change in potential reading at a constant temperature of $25 \pm 1^{\circ} \mathrm{C}$ was recorded for each increment and used to calculate the concentration of the drug sample solution.

\section{Determination of citapolarm hydrobromide in biological fluids}

Aliquots of $5 \mathrm{~mL}$ plasma or urine of a healthy person were placed in 50-ml measuring flasks, and different amounts of CT were added separately with constant shaking. The membrane electrode was immersed in these solutions and potentiometric determination was carried out. The electrode was washed with water between measurements.

\section{RESULTS AND DISCUSSIONS}

\section{Composition of the membrane}

Numerous membrane compositions as indicated in Table 1 were investigated, the excellent performance was obtained by using composition containing $13 \%$ CT-TPB, $43.5 .0 \%$ of each PVC and DBP with resulting slope of $56.83 \mathrm{mV} /$ decade over the concentration range of $1.0 \times 10^{-5}$ to $1.0 \times 10^{-2}$ $\mathrm{mol} / \mathrm{L}$ at $25^{\circ} \mathrm{C}$. The above optimum composition was

Table 1: Composition of different CT membranes and slopes of the corresponding calibration graphs at $25.0^{\circ} \mathrm{C}$

\begin{tabular}{lccccc}
\hline & \multicolumn{5}{c}{ Composition \% (w/w) } \\
Membrane & Ion Pair & PVC & DOP & $\begin{array}{c}\text { Slope } \\
\text { mV/decade }\end{array}$ & $\begin{array}{c}\text { RSD }^{\text {a }} \\
\text { (\%) }\end{array}$ \\
\hline a & 3.0 & 48.5 & 48.5 & 38.65 & 0.36 \\
b & 5.0 & 47.0 & 47.0 & 46.00 & 0.26 \\
c & 9.0 & 45.0 & 45.0 & 51.63 & 0.19 \\
d & 13.0 & 43.5 & 43.5 & 56.83 & 0.08 \\
e & 15.0 & 42.5 & 42.5 & 41.61 & 0.34 \\
\hline
\end{tabular}

a Relative standard deviation (three determinations)

Table 2: Selectivity coefficients for the proposed electrode at $25.0^{\circ} \mathrm{C}$

\begin{tabular}{lccc}
\hline Interfering (B) & $\mathrm{K}_{\mathrm{CIT}, \mathrm{B}^{\mathrm{Z+}}}^{\text {pot. }}$ & Interfering (B) & $\mathrm{K}_{\mathrm{CIT}, \mathrm{B}^{\mathrm{Z+}}}^{\text {pot. }}$ \\
\hline Urea & $4.2 \times 10^{-4}$ & $\mathrm{~K}^{+}$ & - \\
Fructose & - & $\mathrm{Na}^{+}$ & $9.8 \times 10^{-2}$ \\
Glucose & $9.0 \times 10^{-3}$ & $\mathrm{Zn}^{2+}$ & $3.8 \times 10^{-2}$ \\
Starch & - & $\mathrm{Co}^{2+}$ & - \\
Maltose & $7.5 \times 10^{-4}$ & $\mathrm{Al}^{3+}$ & $5.2 \times 10^{-2}$ \\
Glycine & $3.5 \times 10^{-3}$ & $\mathrm{Cl}-$ & $3.3 \times 10^{-4}$ \\
Aspartic acid & $6.1 \times 10^{-2}$ & $\mathrm{Br}-$ & - \\
\hline
\end{tabular}

- Negligible interference 
used to prepare membrane electrodes for all further subsequent investigations.

\section{Life time}

The electrode response time was examined for $1.0 \times 10^{-4}-1.0 \times 10^{-2} \mathrm{~mol} / \mathrm{L}$ drug solutions. The measurements sequence was ordered from low to high concentrations. The electrode exhibited a fast and dynamic response of $25 \mathrm{~s}$ for a period of 30 days, without significant change in the electrode parameters.

\section{Optimization of $\mathrm{pH}$}

The effect of $\mathrm{pH}$ of the CT test solution $\left(1.0 \times 10^{-4} \_1.0 \times 10^{-2} \mathrm{~mol} / \mathrm{L}\right)$ on the electrode potential was investigated by following the potential variation with change in $\mathrm{pH}$ by the addition of small amount of $\mathrm{HCl}$ and/or $\mathrm{NaOH}(0.1-1 \mathrm{~mol} / \mathrm{L}$ of each). It was cleared that the electrode do not respond to $\mathrm{pH}$

Table 3: Determination of citapolarm hydrobromide in pure solutions applying the standard addition method at $25.0^{\circ} \mathrm{C}$

\begin{tabular}{lcc}
\hline $\begin{array}{l}\text { Added } \\
\text { concentration } \\
(\mathrm{mg} / \mathrm{ml})\end{array}$ & $\begin{array}{c}\text { Recovery } \\
(\%)\end{array}$ & RSD* $^{*}$ \\
\hline 2 & 100.0 & 1.18 \\
3 & 102.5 & 0.40 \\
5 & 99.8 & 1.66 \\
\multicolumn{3}{c}{ Average recovery } \\
\hline
\end{tabular}

${ }^{*} \mathrm{RSD}$ (three determination) changes in the range 3.4-7.8. At a pH less than 3.4, the response of electrode increased as the analyte acidity increase; the membrane may extract $\mathrm{H}+$, leading to noisy responses. Because of the formation of non-protonated dimethyl amino group, the gradual decrease in potential noticed at a $\mathrm{pH}$-value more than 7.8 , which leads to a consequent decrease in its concentration.

\section{Selectivity measurements}

The effect of different basic materials on the electrode response was detected by measuring the potentiometric interference from many inorganic cations, sugars, organic, and amino acids. The values of selectivity coefficient for the proposed electrode which shown in Table 2 were very small, this means that there is no interference of these cations with the response of CT electrode. Because of their ionic size, and consequently in their permeabilites and

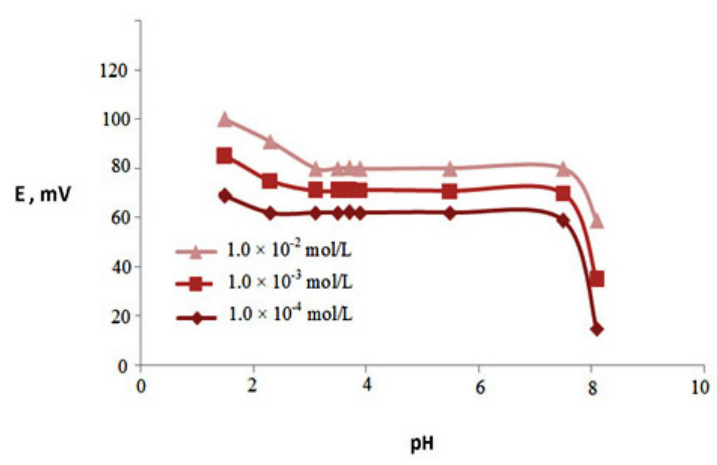

Fig. 2: Effect of $\mathrm{pH}$ of the test solutions on the potential response of electrode at $25.0^{\circ} \mathrm{C}$

Table 4: Determination of citapolarm hydrobromide in spiked plasma and urine samples applying the standard addition method at $25.0^{\circ} \mathrm{C}$

\begin{tabular}{lcccc}
\hline & \multicolumn{2}{c}{ Spiked urine } & \multicolumn{2}{c}{ Spiked plasma } \\
$\begin{array}{l}\text { Added } \\
\text { concentration } \\
(\mathrm{mg} / \mathrm{ml})\end{array}$ & $\begin{array}{c}\text { Recovery } \\
(\%)\end{array}$ & RSD* $^{*}$ & $\begin{array}{c}\text { Recovery } \\
(\%)\end{array}$ & \\
\hline 1.5 & & & & \\
2.5 & 100.80 & 0.72 & 98.90 & 0.52 \\
3.5 & 97.63 & 2.44 & 100.04 & 0.37 \\
5 & 99.18 & 1.12 & 99.44 & 0.81 \\
Average & 99.95 & 1.04 & 101.11 & 0.15 \\
recovery & 99.39 & & 99.87 & \\
\hline
\end{tabular}

${ }^{*} \mathrm{RSD}$ (three determination) 
mobilities comparing to drug, the inorganic cations did not have any interfere. In the case of amino acids and sugars, the high selectivity is mainly attributed to the lipophilic nature of their molecules relative to CT cation and to the difference in polarity.

\section{Regeneration of CT CWE}

After working for a long time with the electrode, it becomes exhausted, so a regeneration procedure was done by soaking the exhausted electrode for $12 \mathrm{~h}$ in a solution of $1.0 \times 10^{-3} \mathrm{~mol} / \mathrm{L} \mathrm{CT}$ solution. The slope was increasing from $53.7 \mathrm{mV} /$ decade to $56.3 \mathrm{mV} /$ decade after regeneration. The reproducibility of repeated measurements on the same solutions was $\pm 1 \mathrm{mV}$.

\section{Analytical Applications}

The proposed electrode was successfully employed for the determination of CT in pure solution, plasma and spiked urine by direct potentiometry using the standard addition method. The obtained average recovery and relative standard deviation values are summarized in Tables 3 and 4 respectively, which reflect the high accuracy and precision of the electrode.

\section{CONCLUSION}

A coated wire citapolarm-selective electrode based on incorporation of citapolarmtetraphenylborate ion pair in a poly(vinylchloride) coating membrane was constructed and used for determining citapolarm $\mathrm{HBr}$ in pure form, urine and serum. The proposed ion-selective electrode has shown good performance characteristics with time stability up to five weeks. The good recoveries and low relative standard deviation reflect the high accuracy and precision of the proposed method. Moreover, the procedure is simple, easy to operate and it is inexpensive determination to make the electrode, therefore, an excellent tool for the routine determination of CT in quality control laboratories.

\section{ACKNOWLEDGMENTS}

This research project was supported by a grant from the Deanship of Scientific Research. Princess Nourah Bint Abdul Rahman University.

\section{REFERENCES}

1. Marjoribanks, J.; Brown, J.; O’Brien, P.M.; Wyatt, K.; "Selective serotonin reuptake inhibitors for premenstrual syndrome. Cochrane Database Syst Rev. 2013

2. Tiihonen, J.; Ryynänen, O.P.; Kauhanen, J.; Hakola, H.P.; Salaspuro, $M$. Pharmacopsychiatry (1996), 29, 27-9.

3. Sindrup, S.H.; Bjerre, U.; Dejgaard, A.; Brøsen, K.; Aaes-Jørgensen, T, Gram, L.F. Clin. Pharmacol. Ther. (1992), 52, 547-52.

4. Raza, A. Chem. Pharm. Bull. (2006), 54, 432434.

5. Darwish, I. A.; Refaat, I. H.; J. AOAC Int. (2006), 89, 326-333.

6. Menegola, J.; Steppe, M.; Schapoval, E.E.S.; J. AOAC Int. (2008), 91, 52-58.

7. Narayana, B.; Veena, K. J. Mex. Chem. Soc. (2010), 54, 98-102.

8. Halvorsen, T. G.; Pedersen-Bjergaard, S.; Rasmusse, K. E. J. Chromatogr. A (2001), 909, 87-93.

9. Rong, Z.; Shangyou, X.; Hongmei, X.; Rui,
H.; Zhining, X. Chin. j. Anal. Chem. (2006), 34, 1384-1388.

10. Nevado, J.J.B.; Cabanillas, C. G.; Llerena, M.J.V,; Robledo, V. R., J. Chromatogr. A (2005), 1072, 249-257.

11. Berzas, J.J.; Guiberteau, C.; Villasenor, M.J.; Rodriguez, V. Anal. Chim. Acta , (2004), 519, 219-230.

12. Saravanan, M.T.C.; Kumar, C.A.S.; Sudhakar, C.; Rajesh, B.; Kumar, G.S. JASR. 2012, 3, 62.

13. Pistos, C.; Panderi, I.; Atta-Politou, J.; J. Chromatogr. B 2004, 810, 235-244.

14. Rao, R. N.; Raju, A. N.; Nagaraju, D. J. Pharm. Biomed. Anal. (2006), 41, 280-285.

15. Sujatha, K.; Rao, J. V. L. N. S. Pharmanest. (2013), 4,1299-1605.

16. Baumann, E. Anal. Chim. Acta (1986), 42, 127-132.

17. Moffat, A.C.; Jackson, J.V.; Moss, M.S. ; Widdop, B. The pharmaceutical press: London,(1986), 794. 